Daisuke Harada*, Kaoru Ueyama, Kyoko Oriyama, Yoshihito Ishiura, Hiroko Kashiwagi, Hiroyuki Yamada and Yoshiki Seino

\title{
Switching from conventional therapy to burosumab injection has the potential to prevent nephrocalcinosis in patients with $\mathrm{X}$-linked hypophosphatemic rickets
}

https://doi.org/10.1515/jpem-2020-0734

Received December 23, 2020; accepted March 8, 2021; published online April 12, 2021

\section{Abstract}

Objectives: $\mathrm{X}$-linked hypophosphatemic rickets (XLH) is a congenital fibroblast growth factor (FGF)23-related metabolic bone disease that is treated with active vitamin $\mathrm{D}$ and phosphate as conventional therapies. Complications of these therapies include nephrocalcinosis (NC) caused by excessive urine calcium and phosphate concentrations. Recently, an anti-FGF23 antibody, burosumab, was developed and reported to be effective in poorly-controlled or severe XLH patients. This study aimed to reveal the impact of switching treatments in relatively well-controlled XLH children with the Rickets Severity Scale less than 2.0.

Methods: The effects of the two treatments in eight relatively well-controlled XLH children with a mean age of $10.4 \pm 1.9$ years were compared retrospectively for the same treatment duration (31 \pm 11 months) before and after the baseline.

Results: Actual doses of alfacalcidol and phosphate as conventional therapy were $150.9 \pm 43.9 \mathrm{ng} / \mathrm{kg}$ and $27.5 \pm 6.3$ $\mathrm{mg} / \mathrm{kg}$ per day, respectively. Renal echography revealed spotty NC in $8 / 8$ patients, but no aggravation of NC was detected by switching treatments. Switching treatments increased TmP/GFR $(\mathrm{p}=0.002)$ and \%TRP $(\mathrm{p}<0.001)$, and improved the high urine calcium/creatinine ratio to the normal range $(\mathrm{p}<0.001)$ although both treatments controlled disease markers equally. Additionally, low

*Corresponding author: Daisuke Harada, MD, PhD, Departmen of Pediatrics, Osaka Hospital, Japan Community Healthcare Organization (JCHO), 4-2-78 Fukushima, Fukushima-ku, Osaka 553-0003, Japan, Phone: +81 66441 5451, Fax: +81 66445 8900, E-mail: harada-d@nifty.com

Kaoru Ueyama, Kyoko Oriyama, Yoshihito Ishiura, Hiroko Kashiwagi, Hiroyuki Yamada and Yoshiki Seino, Department of Pediatrics, Osaka Hospital, Japan Community Healthcare Organization (JCHO), Osaka, Japan intact parathyroid hormone during conventional therapy was increased within the normal range by switching treatments.

Conclusions: Our results suggest that a high dose of alfacalcidol was needed to control the disease, but it caused hypercalciuria and NC. We concluded that switching treatments in relatively well-controlled XLH children improved renal phosphate reabsorption and decreased urine calcium extraction, and may have the potential to prevent NC.

Keywords: burosumab; hypercalciuria; nephrocalcinosis; neural phosphate; vitamin D; X-linked hypophosphatemic rickets.

\section{Introduction}

X-linked hypophosphatemic rickets (XLH) [OMIM\#307800] is a congenital metabolic bone disease characterized by short stature, genu varum/valgum, fraying, or cupping in the metaphysis, and increased serum alkaline phosphatase (ALP), caused by hypophosphatemia [1-3]. XLH is caused by mutations in the phosphate regulating neutral endopeptidase (PHEX) gene [OMIM*300550] and is inherited as an X-chromosomal dominant trait [4]. Although the pathogenic mechanisms are not understood completely, the hypersecretion of fibroblast growth factor 23 (FGF23) in XLH patients decreases vitamin D activation and suppresses the reabsorption of phosphate $(\mathrm{P})$ in renal tubules, leading to hypophosphatemia [5, 6].

Active vitamin D and phosphate are administrated to XLH patients as conventional therapies to improve hypophosphatemia and rickets [7]. In adulthood, nephrocalcinosis (NC), nephrolithiasis, and impaired renal function occur in XLH patients as complications related to conventional therapy $[8,9]$. NC is caused by hypercalciuria and excessive urine $\mathrm{P}$ concentration [10-12]. Because NC can cause nephrolithiasis, careful follow-up is essential [13, 14]. Although conventional therapy is moderately effective for 
XLH, oral active vitamin D and phosphate, or both, can promote or worsen NC related to drug-induced hypercalciuria in addition to the impaired reabsorption of phosphate by the disease itself $[7,15,16]$.

Recently, an anti-FGF23 antibody, burosumab, was developed as a fundamental treatment for FGF23-related hypophosphatemic diseases [17-19]. Compared with conventional therapy, burosumab improved disease symptoms and clinical data in severe or poorly-controlled XLH patients, with the Rickets Severity Scale (RSS) of 2.0 or more, in a randomized controlled clinical trial (RCT) [20]. However, the effect of burosumab in relatively wellcontrolled XLH patients, with RSS below 2.0, by conventional therapy has not been evaluated thoroughly and the benefits of switching treatments are key clinical issues to be elucidated.

\section{Patients and methods}

\section{Study design}

This study aimed to reveal the impact of switching treatments from conventional therapy to burosumab in relatively well-controlled XLH children with RSS below 2.0.

We retrospectively analyzed the clinical data of pediatric XLH patients during conventional therapy and burosumab injection (Figure 1). Before initiating burosumab injection, we set the baseline after four weeks as the washout period for conventional therapy. Because the clinical severity or control status of XLH patients varies, the effects of the two treatments were compared for the same treatment duration ( $31 \pm 11$ months) in each patient before and after the baseline.

\section{Patients}

Overall, 28 XLH patients, 13 children, and 15 adults were treated with conventional therapy in our hospital. Because clinical trials for switching treatments to burosumab was for only pediatric patients, of these, informed consent was obtained from the parents of 13 pediatric XLH patients at enrollment to the RCT (UX023-CL301) [20] in December 2016, at enrollment to the self-injection trial (KRN23-003) in July 2017, and/or after burosumab approval in Japan in November 2019. Poorlycontrolled XLH patients, with RSS of 2.0, participated in the RCT [20] and patients and/or parents/family members chose their own treatments. Two patients were enrolled in the RCT, five participated in the self-injection trial, and one initiated burosumab after its approval. Consequently, eight patients treated with burosumab were enrolled in this study. Informed consent was obtained from all individual participants included in this study.

\section{Treatments}

For conventional therapy, $50-100 \mathrm{ng} / \mathrm{kg}$ per day of alfacalcidol (Alfarol $^{\circledR}$, Chugai Pharmaceutical Co., Ltd., Tokyo, Japan, or Onealfa ${ }^{\circledR}$, Teijin Pharmaceutical Company, Tokyo, Japan) and/or 20-40 mg/kg per day of neural phosphate (Phosribbon ${ }^{\circledR}$ Combination granule, ZERIA Pharmaceutical Co., Ltd., Tokyo, Japan) were administered at diagnosis. We set the most important clinical goal as to control rickets. We adjusted the doses of the drugs monitoring bone X-rays and biochemical data particularly the serum ALP concentration. We also monitored the urine $\mathrm{Ca} / \mathrm{Cre}$ ratio not to exceed about $0.3-0.4 \mathrm{mg} / \mathrm{mg}$.

Burosumab (CRYSViTA ${ }^{\circledR}$ Subcutaneous Injection, Kyowa Kirin Co., Ltd, Tokyo, Japan) was administrated by subcutaneous injection at doses of $0.8-1.2 \mathrm{mg} / \mathrm{kg}$ every two weeks, adjusting in relation to serum $\mathrm{P}$ concentrations above $3.0 \mathrm{mg} / \mathrm{dL}$ which was the criterion of the clinical trials.

\section{Data analysis}

Biochemical analyses and bone $\mathrm{X}$-rays were performed every 3-4 months and every six months, respectively, in the RCT (UX023-CL301) [20], in the following continuous administration trial (KRN23-004), in the selfinjection trial (KRN23-003), or within clinical practice in our hospital. The RSS was used to evaluate rickets status as previously reported [21]. Briefly, rickets status in the metaphysis of four long bones (distal femur, proximal tibia, distal radius, and distal ulna) was scored from 0 (normal) to 10 (most severe). RSS was evaluated blindly by three specialists.

Renal echography was performed and the severity of NC was assessed as previously described on a scale of $0-4$, with 0 indicating normal, 1 indicating mild echogenicity around the medullary pyramids border, 2 more intense echogenic rims with echoes faintly filling the entire pyramid, 3 uniformly intense echoes throughout the pyramid, and 4 indicating stone formation $[7,11,22]$. In a kidney indicating all severity including grade 0 , high echoic dots may be detected (Figure 2). In this study, we diagnosed over three dots less than $3 \mathrm{~mm}$ in diameter in a kidney as mild spotty NC [23]. The severity of NC was also evaluated blindly by three specialists.

Genetic analysis of the PHEX gene was performed by direct sequencing.

Blood and urine tests were performed in a fasting state. Urine samples were the second urination of the day. Serum/urine concentrations of calcium (Ca) and creatinine (Cre) were measured in or after the clinical trials by Arsenazo III, an enzymatic method (sarcosine oxidase-peroxidase) (Aqua Auto Kinos Ca reagents, Kainos Laboratories, Inc., Tokyo, Japan; Serotec Ca-AL, Serotec Co., Ltd., Sapporo, Japan), and electrochemiluminescence immunoassay (ECLIA) (L system CRE, Sysmex Corporation, Kobe, Japan; Determiner L CRE, Hitachi Chemical Diagnostics Systems Co., Ltd.,

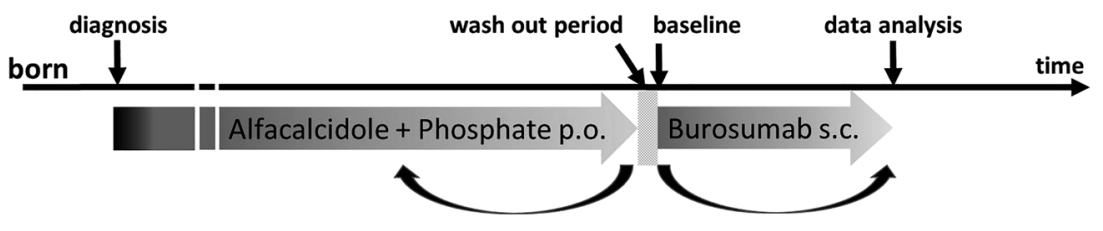

Figure 1: Schematic representation of study design. 

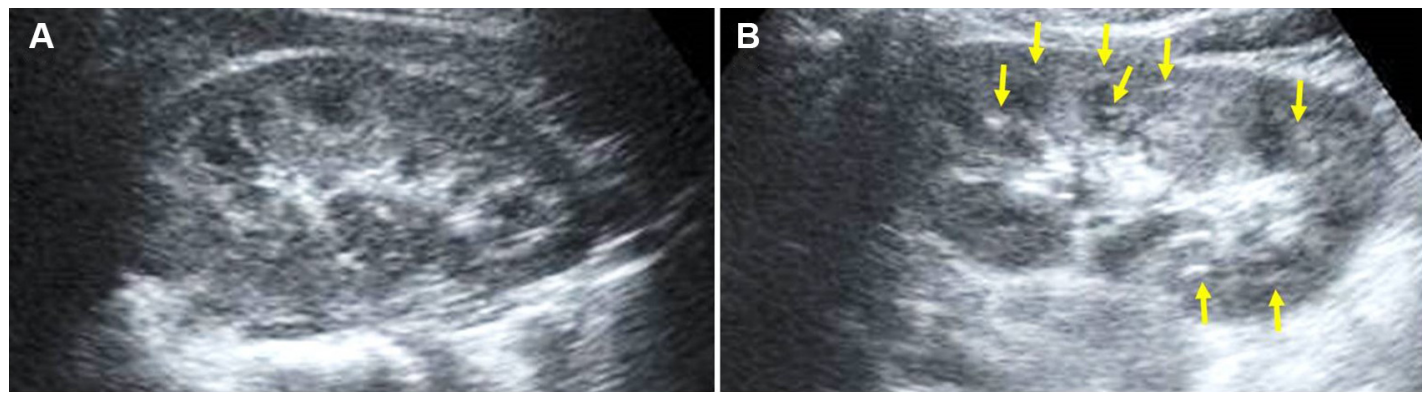

Figure 2: Echographic analysis of kidney.

(A) Grade 1 of nephrocalcification in patient 1. (B) High echoic dots (arrows) considered as mild nephrocalcinosis in patient 5 grading 0.

Tokyo, Japan), respectively. Serum intact parathyroid hormone (iPTH) and 1,25-dihydoxy vitamin D [1,25(OH) $\left.)_{2} \mathrm{D}\right]$, and FGF23 were measured by ECLIA (ECLusys PTH-intact: Roche Diagnostics K.K., Tokyo, Japan), double-antibody radioimmunoassay (RIA2) $\left(1,25(\mathrm{OH})_{2} \mathrm{D}\right.$ RIA kit, Immunodiagnostic Systems Limited, Boldon, UK), and chemiluminescent enzyme immune assay (Determiner CL FGF23, Hitachi Chemical Diagnostics Systems Co., Ltd., Tokyo, Japan), respectively. Serum ALP activities were detected using the International Federation of Clinical Chemistry and Laboratory Medicine (IFCC) method (ALP2 Reagents, Roche Diagnostics Corporation, IN, USA) in the RCT [20] and the modified Japan Society of Clinical Chemistry Reference (JSCC) method for other data (CicaLiquid ALP, Kanto Kagaku Co. Inc., Tokyo, Japan) [24]. These methods cannot be directly compared, but the formula $x=2.84 \times y(x=$ JSCC, $y=$ IFSS $)$ established by the Japan Society of Clinical Chemistry was used to estimate and compare values [25]. Serum and urine $\mathrm{P}$ were detected with different methods but the reference ranges were the same and considered comparable. Phosphate concentrations were measured by the molybdic acid direct method (IP-HR II, Fujifilm Wako Pure Chemical Corporation, Osaka, Japan) (reference range: 2.5-4.5 mg/dL) and the enzymatic method (UV-end) (IP reagent L "Kokusai", Sysmex Corporation, Kobe, Japan) (reference range: $2.5-4.5 \mathrm{mg} / \mathrm{dL}$ ), respectively, in the clinical trials and in our hospital.

Urine calcium extractions were analyzed in all patients using the spot urine $\mathrm{Ca}$ to urine Cre ratio $(\mathrm{u}-\mathrm{Ca} / \mathrm{Cre})$ constantly, and by $24 \mathrm{~h}$ urine Ca extraction during the clinical trials. Consequently, the $24 \mathrm{~h}$ urine $\mathrm{Ca}$ extraction was evaluated total of 34 times in $7 / 8$ patients. The maximal tubular reabsorption of phosphate per glomerular filtration rate (TmP/GFR) and tubular reabsorption of phosphate (\%TRP) were calculated as follows: serum $\mathrm{P}$ - (urine $\mathrm{P} \times$ serum $\mathrm{Cr}$ )/urine $\mathrm{Cr}(\mathrm{mg} / \mathrm{dL})$, and $\{1$ - (urine $\mathrm{P} \times$ serum $\mathrm{Cr} /$ serum $\mathrm{P} \times$ urine $\mathrm{Cr}$ ) $\} \times 100$ (\%), respectively.

\section{Statistical analysis}

The mean values of biochemical data and RSS were calculated for each patient during conventional therapy and burosumab treatment. To evaluate the course of serum and urine biochemical data, and X-rays, one-way analysis of variance (ANOVA) for repeated measures and general linear model repeated measures were performed. The mean values for baseline, conventional therapy, and burosumab were compared. Mauchly's sphericity test was applied and, if necessary, technical corrections were made using the Greenhouse-Geisser test. Multiple comparisons were analyzed by Bonferroni's test. Pearson's correlation coefficient was calculated to compare the correlation between the two methods (spot sample and $24 \mathrm{~h}$ sample) for urine $\mathrm{Ca}$ extraction. All statistical analyses were performed using SPSS software V23.0 (IBM, Japan, Tokyo). A p-value $<0.05$ was considered statistically significant.

\section{Ethical approval}

This study was approved by the Medical Ethic Committee of JCHO Osaka Hospital (ID: 2020-04) for collection and analysis of the clinical data. All procedures performed in studies involving human participants were in accordance with the ethical standards of the institutional and/or national research committee and with the 1964 Helsinki declaration and its later amendments or comparable ethical standards. Written informed consent was obtained from all individuals included in this study.

\section{Results}

The backgrounds of the patients are summarized in Table 1. Two male patients were included in the eight participants (25\%). Clinical diagnosis of XLH was determined at infancy ( $0.5 \pm 0.2$ years of age) and later it was confirmed by mutational analysis of the PHEX gene in all patients. The duration of conventional therapy was $9.8 \pm 2.1$ years and burosumab injection was started at $10.4 \pm 1.9$ years of age. At baseline, the mean height and BMI were $-1.41 \pm 0.75 \mathrm{SD}$ (range: -0.64 to -2.52 ) and $-0.84 \pm 0.58$ SD (range: -0.32 to -1.82$)$, respectively. Patients were administrated alfacalcidol and phosphate as conventional therapies. The actual dose of alfacalcidol was $150.9 \pm 43.9 \mathrm{ng} / \mathrm{kg}$ per day through the analysis period (range: 85-227). Oral phosphate was prescribed at $27.5 \pm 6.3 \mathrm{mg} / \mathrm{kg}$ per day throughout the analysis period (range: 14.6-40.5) 3-4 times a day.

At baseline after four weeks of the washout period, the serum P and FGF23 concentrations were $2.3 \pm 0.3 \mathrm{mg} / \mathrm{dL}$ and $247.8 \pm 157.1 \mathrm{pg} / \mathrm{mL}$, respectively (Table 2). Serum Ca, $\mathrm{ALP}$, and 1,25(OH) ${ }_{2} \mathrm{D}$ were $9.8 \pm 0.2 \mathrm{mg} / \mathrm{dL}, 1,564 \pm 177 \mathrm{U} / \mathrm{L}$, 

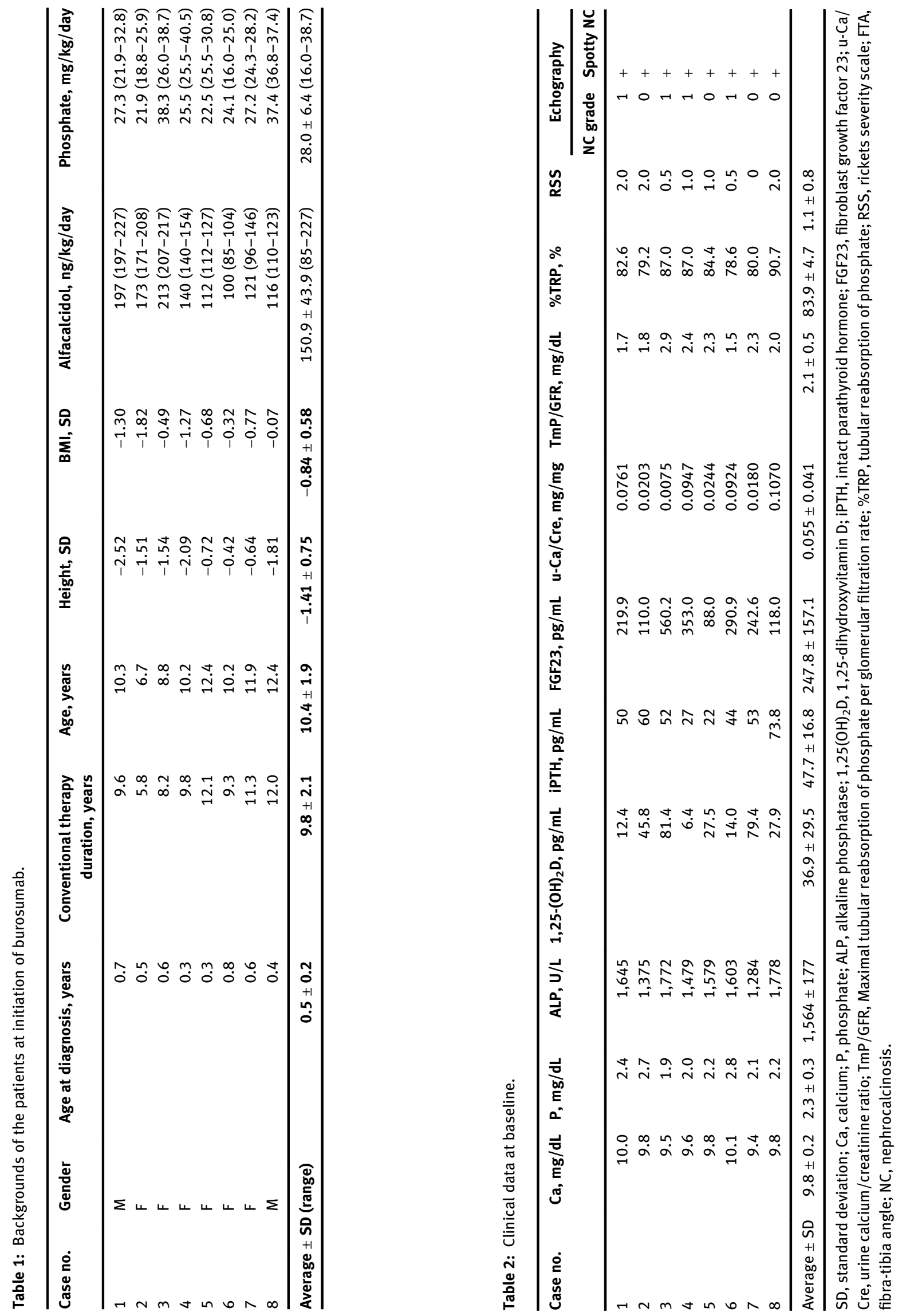
and $36.9 \pm 29.5 \mathrm{pg} / \mathrm{mL}$, respectively. Urine extraction of $\mathrm{Ca}$ and renal reabsorption of $\mathrm{P}$ were assessed as the $\mathrm{u}-\mathrm{Ca} / \mathrm{Cre}$ $(0.055 \pm 0.041 \mathrm{mg} / \mathrm{mg})$, and the TmP/GFR $(2.1 \pm 0.5 \mathrm{mg} / \mathrm{dL})$ and \%TRP $(87.6 \pm 6.1 \%)$, respectively. Bone X-rays to determine rickets status were analyzed by RSS as $1.1 \pm 0.8$ (range: 0.0-2.0). Abdominal echography revealed lowgrade NC in four of eight patients (50\%) and spotty calcifications were observed in all patients (Figure 2).

Burosumab was injected at $1.09 \pm 0.38 \mathrm{mg} / \mathrm{kg}$ every two weeks (range: 0.64-2.04). Mean RSS scores tended to be improved by switching treatment from conventional therapy to burosumab, but this did not reach statistical significance $(F(2,12)=3.54, \quad \mathrm{p}=0.062)$ (Figure 3). After switching treatments, renal echography was performed regularly and showed no aggravation of NC in any patients.

In both conventional therapy and burosumab injection, serum $\mathrm{P} \quad(F(2,14)=8.768, \quad \mathrm{p}=0.003)$, ALP $(F(2,14)=4.385, \mathrm{p}=0.033)$, and $1,25(\mathrm{OH})_{2} \mathrm{D}(F(2,14)=20.983$, $\mathrm{p}<0.001)$ were improved from baseline, but were not different between treatments (Supplementary Material). TmP/GFR and \%TRP were unchanged by conventional therapy when compared with baseline, but they were significantly increased by burosumab injection: $78.4 \pm 9.4$ to $91.6 \pm 5.6 \%(F(2,12)=10.501, \mathrm{p}=0.002)$ and from $2.5 \pm 0.6$ to $3.0 \pm 0.4 \mathrm{mg} / \mathrm{dL}(F(2,12)=15.452, \mathrm{p}<0.001)$, respectively.

Switching treatments decreased serum Ca $(F(2,12)=$ 4.536, $\mathrm{p}=0.034)$ within the normal range and increased $\mathrm{u}-\mathrm{Ca} / \mathrm{Cre}$ to the normal range $(F(2,14)=28.639, \mathrm{p}<0.001)$ (Figure 4). Furthermore, suppressed serum iPTH during conventional therapy was increased within the normal range by washing out the treatment and during burosumab injection $(F(2,14)=0.548, \mathrm{p}<0.001)$ (Figure 4).

To analyze the reliability of spot urine samples, a comparison of spot $\mathrm{u}-\mathrm{Ca} / \mathrm{Cre}$ to $24 \mathrm{~h}$ urine $\mathrm{Ca}$ extraction was performed (Figure 5). Calcium extraction of spot urine samples correlated with that of $24 \mathrm{~h}$ urine samples $(\mathrm{r}=0.61$, $\mathrm{p}<0.001)$.

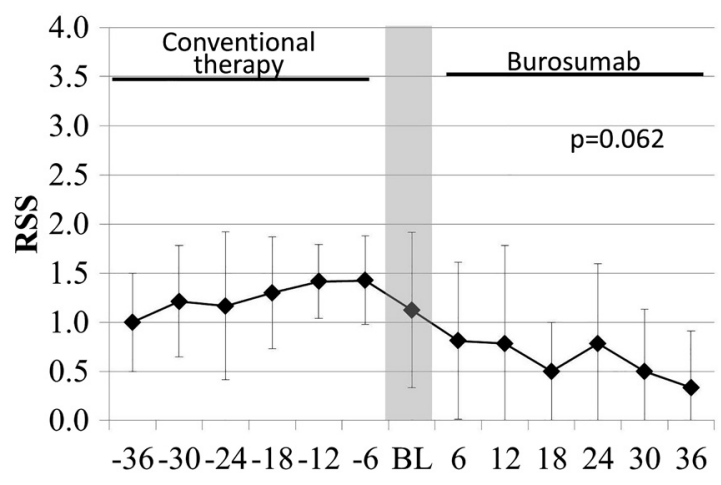

Treatment Duration (months)

Figure 3: Rickets severity scale (RSS) in bone X-rays.

\section{Discussion}

In the present study, burosumab improved the renal reabsorption of $\mathrm{P}$ (TmP/GFR and \%TRP) compared to that at the baseline, which was unchanged by conventional therapy. These data demonstrate burosumab is a useful treatment for XLH and reproduced the results of a previous RCT [20].

Burosumab also tended to improve rickets in partlycontrolled XLH children. A statistical difference was not detected in our study possibly because disease in our patients was already partly controlled. Indeed, RSS and height SD scores were relatively good during conventional therapy. To treat XLH children, we believe the most important goal is not to control biochemical defects but to control rickets in growing bones. Improved rickets should lead to good growth minimizing deformity of legs or short stature. Thus we adjusted doses of the drugs referring to $\mathrm{X}$-rays paying attention to side effects including urine $\mathrm{Ca}$ extraction. Consequently, rickets in our patients were controlled with the conventional therapy instead of overdose active vitamin D. Large doses of active vitamin D increase the risk of hypercalciuria [15]. Although initial dose of alfacalcidol was recommended 30-50 ng/ $/ \mathrm{kg} / \mathrm{day}$ [26], actual clinical dose was reported $110 \pm 0.04 \mathrm{ng} / \mathrm{kg} / \mathrm{day}$ [27]. Overdoses of alfacalcidol in our patients may be in a gap between the recommendation and the clinical necessity. From this report, we could say that burosumab injection therapy dissolves this dilemma and is worth to be switched from the conventional therapy beyond the cost.

At baseline, frequent $\mathrm{NC}$, increased serum $\mathrm{Ca}$, and increased $\mathrm{u}-\mathrm{Ca} / \mathrm{Cre}$ were observed as possible side effects of the conventional therapy. Burosumab did not develop or worsen NC. Because the cutoff value of hypercalciuria in spot $\mathrm{u}-\mathrm{Ca} / \mathrm{Cre}$ has been reported to be $0.13-0.18$ [28, 29], $\mathrm{u}-\mathrm{Ca} / \mathrm{Cre}$ during conventional therapy was often diagnosed as hypercalciuria. Switching treatments dissolved hypercalciuria to the normal range and may be useful for the reduction of side effects caused by conventional therapy although both treatments controlled disease markers equally (serum $\mathrm{P}, \mathrm{ALP}$, and $1,25(\mathrm{OH})_{2} \mathrm{D}$ ).

Intact PTH was increased within normal range after switching treatments. Because iPTH was already increased by washout of alfacalcidol administration, one possible cause may be a direct effect of hypervitaminosis D [30]. As the other possibility, endogenous PTH secretion may have been suppressed by excess serum Ca concentration provably because of the high dose of alfacalcidol. This assumption is partially supported by consequent hypercalciuria during the therapy. Through these ways, switching treatments can normalize serum iPTH levels. 

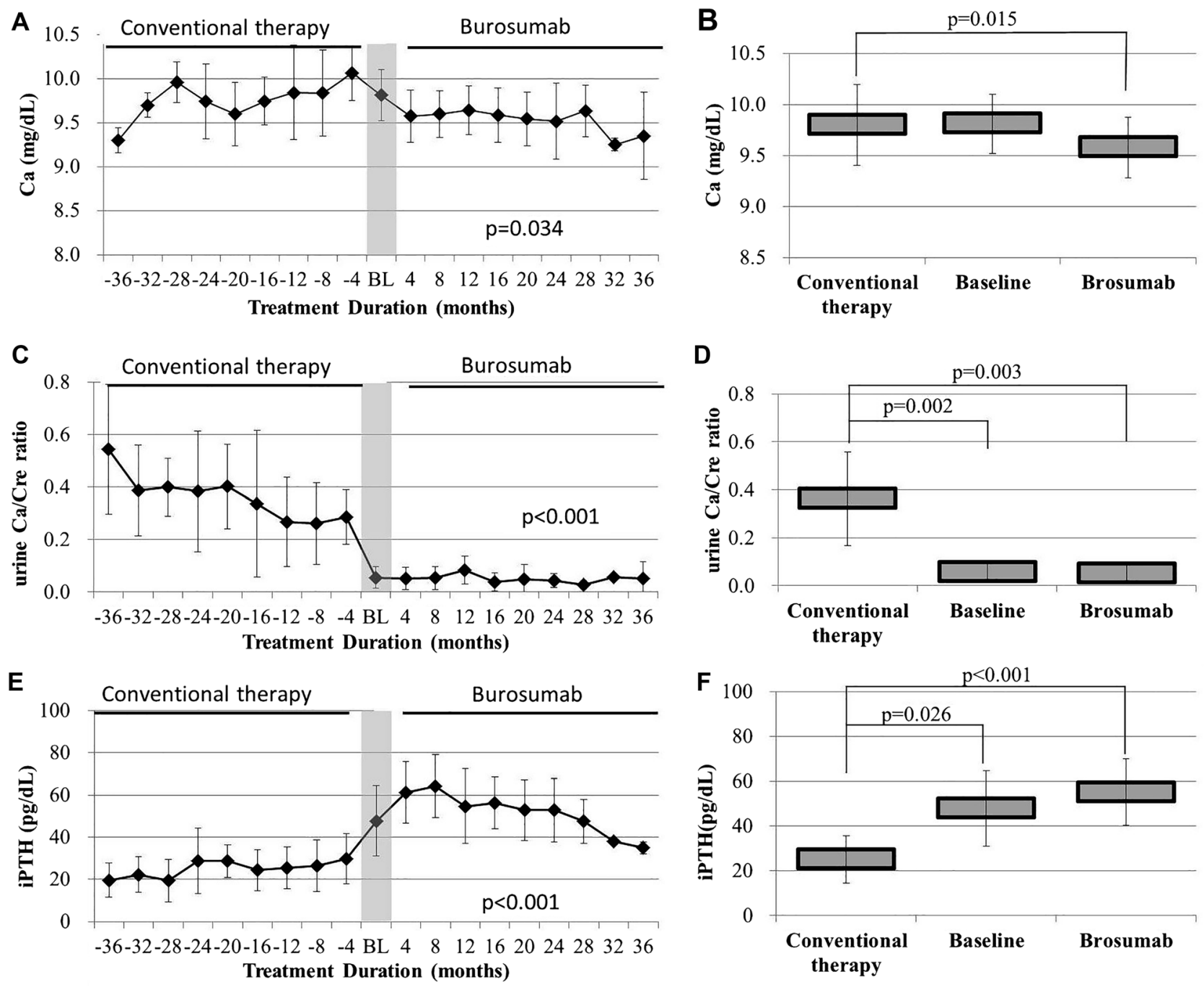

Figure 4: The impact of switching treatments on calcium metabolism.

Switching treatments decreased serum $\mathrm{Ca}(\mathrm{A}, \mathrm{B})$ and $\mathrm{u}-\mathrm{Ca} / \mathrm{Cre}(\mathrm{C}, \mathrm{D})$ from $9.7 \pm 0.4$ to $9.5 \pm 0.3 \mathrm{mg} / \mathrm{dL}(\mathrm{p}=0.015)$, and from $0.359 \pm 0.195$ to $0.056 \pm 0.044 \mathrm{mg} / \mathrm{mg}(\mathrm{p}=0.003)$, respectively. On the other hand, $i$ PTH (E, F) was increased from $25.9 \pm 10.9$ to $55.9 \pm 15.3 \mathrm{pg} / \mathrm{mL}$ by switching treatments $(p<0.001)$.

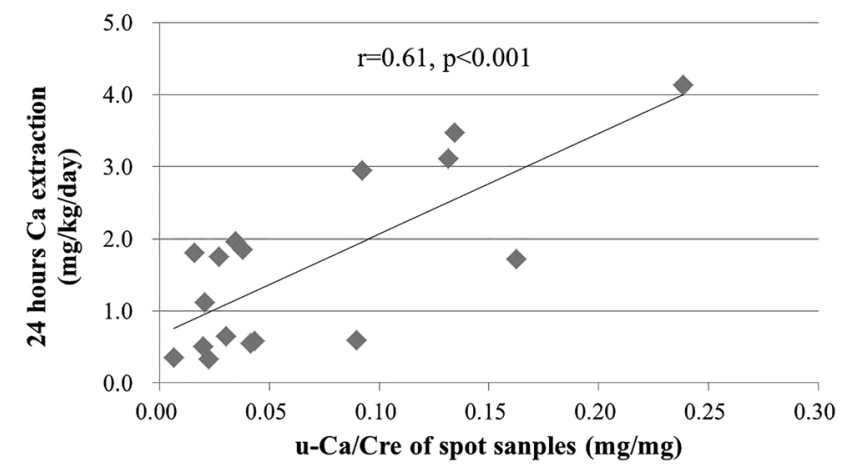

Figure 5: Correlation analysis of spot $\mathrm{u}-\mathrm{Ca} / \mathrm{Cre}$ and $24 \mathrm{~h}$ Ca extraction. Spot $\mathrm{u}-\mathrm{Ca} / \mathrm{Cre}$ were correlated with urine $\mathrm{Ca}$ extraction in $24 \mathrm{~h}$ samples $(r=0.608, p<0.001)$.
Hypercalciuria and high levels of urine P cause NC, and therefore oral vitamin $\mathrm{D}$ and phosphate may be major causes for developing NC in XLH patients treated with conventional therapy [12, 31-33]. The degree of NC varies from histologically subtle forms such as NC or Randall's plaque, which may not be detected by echography to advanced NC that is visible by X-rays [12, 34]. High echoic dots in the renal medulla should be assessed as mild NC although the echographic grading scale of NC judges them 0 (no abnormalities). To assess them in an objective manner, we set diagnostic criteria as over three dots less than $3 \mathrm{~mm}$ in diameter in a kidney. Several pathways for developing nephrolithiasis have been suggested and some 
forms of NC lead to nephrolithiasis [12, 35, 36]. Consistent with our data, no past clinical studies have reported that burosumab induced or aggravated NC [37-39]. Thus, switching treatments, which decreased urine $\mathrm{Ca}$ and $\mathrm{P}$ extraction, is expected to decrease the risk of $\mathrm{NC}$ and nephrolithiasis.

In conclusion, this study demonstrated that burosumab improved renal $\mathrm{P}$ reabsorption in partly-controlled XLH children compared with conventional therapy. Because high doses of alfacalcidol and phosphate as conventional therapy were needed to control rickets in XLH children, switching treatments to burosumab injection can dissolve side effects associated with conventional therapy. Moreover, switching treatments decreased urine Ca extraction indicating it may have the potential to prevent $\mathrm{NC}$.

Acknowledgments: Part of this study was included in phase III clinical trial and the following KRN23-004 and KRN23003 studies conducted by Kyowa-Kirin Ltd. Kyowa-Kirin Ltd. provided biochemical data within the clinical trials. We would like to thank our patients and their families for agreeing to participate and for providing data through their medical records. We appreciate Dr. Noriyuki Namba and the clinical trial coordinators for translation among clinical staff, patients, and the pharmaceutical company. We also express our gratitude to the clinical staff of Osaka Hospital, JCHO. We thank J. Ludovic Croxford, PhD, from Edanz Group (https://en-author-services.edanzgroup.com/ac) for editing a draft of this manuscript.

Research funding: This study was funded in part by a grant from the Foundation for Growth Science 2020 (receipt number: 32) (D.H.).

Author contributions: All the authors were involved in the clinical management of the patients and reviewed the data and the manuscript. DH and YS designed the study. DH obtained and analyzed most of the data. DH wrote the paper. All authors have accepted responsibility for the entire content of this manuscript and approved its submission.

Competing interests: The authors declare that they have no conflict of interest.

Informed consent: Written informed consent was obtained from all individuals included in this study.

Ethical approval: This study was approved by the Medical Ethic Committee of JCHO Osaka Hospital (ID: 2020-04) for collection and analysis of the clinical data. All procedures performed in studies involving human participants were in accordance with the ethical standards of the institutional and/or national research committee and with the 1964 Helsinki declaration and its later amendments or comparable ethical standards.

\section{References}

1. Albright F, Butler AM, Bloomberg E. Rickets resistant to vitamin D therapy. Arch J Dis Child 1937;54:529-47.

2. Lobaugh B, Drezner MK. Abnormal regulation of renal 25-dihydroxyvitamin D-1 $\alpha$-hydroxylase activity in the $\mathrm{X}$-linked hypophosphatemic mouse. J Clin Invest 1983;71:400-3.

3. Endo I, Fukumoto S, Ozono K, Namba N, Inoue D, Okazaki R, et al. Nationwide survey of fibroblast growth factor 23 (FGF23)-related hypophosphatemic diseases in Japan: prevalence, biochemical data and treatment. Endocr J 2015;62:811-6.

4. Francis F, Hennig $S$, Korn B, Reinhardt R, de Jong P, Poustka A, et al. A gene (PEX) with homologies to endopeptidases is mutated in patients with X-linked hypophosphatemic rickets. Nat Genet 1995;11:130-6.

5. Gattineni J, Bates C, Twombley K, Dwarakanath V, Robinson ML, Goetz R, et al. FGF23 decreases renal NaPi-2a and NaPi-2c expression and induces hypophosphatemia in vivo predominantly via FGF receptor 1. Am J Physiol Ren Physiol 2009; 297:F282-91.

6. Shimada T, Hasegawa H, Yamazaki Y, Muto T, Hino R, Takeuchi Y, et al. FGF-23 is a potent regulator of vitamin D metabolism and phosphate homeostasis. J Bone Miner Res 2004;19:429-35.

7. Costa T, Marie PJ, Scriver CR, Cole DE, Reade TM, Nogrady B, et al. $X$-linked hypophosphatemia: effect of calcitriol on renal handling of phosphate, serum phosphate, and bone mineralization. J Clin Endocrinol Metab 1981;52:463-72.

8. Skrinar A, Dvorak-Ewell M, Evins A, Macica C, Linglart A, Imel EA, et al. The lifelong impact of X-linked hypophosphatemia: results from a burden of disease survey. J Endocr Soc 2019;3:1321-34.

9. Chesher D, Oddy M, Darbar U, Sayal P, Casey A, Ryan A, et al. Outcome of adult patients with X-linked hypophosphatemia caused by PHEX gene mutations. J Inherit Metab Dis 2018;41: 865-76.

10. Verge CF, Lam A, Simpson JM, Cowell CT, Howard NJ, Silink M, et al. Effects of therapy in X-linked hypophosphatemic rickets. $\mathrm{N}$ Engl J Med 1991;325:1843-8.

11. Shavit L, Ferraro PM, Johri N, Robertson W, Walsh SB, Moochhala $\mathrm{S}$, et al. Effect of being overweight on urinary metabolic risk factors for kidney stone formation. Nephrol Dial Transplant 2015; 30:607-13.

12. Pozdzik A, Maalouf N, Letavernier E, Brocheriou I, Body JJ, Vervaet B, et al. Meeting report of the "symposium on kidney stones and mineral metabolism: calcium kidney stones in 2017". J Nephrol 2019;32:681-98.

13. Habbig S, Beck BB, Hoppe B. Nephrocalcinosis and urolithiasis in children. Kidney Int 2011;80:1278-91.

14. Hoppe B, Kemper MJ. Diagnostic examination of the child with urolithiasis or nephrocalcinosis. Pediatr Nephrol 2010;25: 403-13.

15. Carpenter TO, Imel EA, Holm IA, de Beur SMJ, Insogna KL. A clinician's guide to X-linked hypophosphatemia. J Bone Miner Res 2011;26:1381-8.

16. Makitie O, Doria A, Kooh SW, Cole WG, Daneman A, Sochett E. Early treatment improves growth and biochemical and radiographic outcome in X-linked hypophosphatemic rickets. J Clin Endocrinol Metab 2003;88:3591-7.

17. Carpenter TO, Imel EA, Ruppe MD, Weber TJ, Klausner MA, Wooddell MM, et al. Randomized trial of the anti-FGF23 antibody 
KRN23 in X-linked hypophosphatemia. J Clin Invest 2014;124: 1587-97.

18. Imel EA, Zhang X, Ruppe MD, Weber T, Klausner MA, Ito T, et al. Prolonged correction of serum phosphorus in adults with X-linked hypophosphatemia using monthly doses of KRN23. J Clin Endocrinol Metab 2015;100:2565-73.

19. Cheong HI, Yoo HW, Adachi M, Tanaka H, Fujiwara I, Hasegawa Y, et al. First-in-Asian phase I study of the anti-fibroblast growth factor 23 monoclonal antibody, burosumab: safety and pharmacodynamics in adults with X-linked hypophosphatemia. JBMR Plus 2019;3:e10074.

20. Imel EA, Glorieux FH, Whyte MP, Munns CF, Ward LM, Nilsson O, et al. Burosumab versus conventional therapy in children with X-linked hypophosphataemia: a randomised, active-controlled, open-label, phase 3 trial. Lancet 2019;393:2416-27.

21. Thacher TD, Pettifor JM, Tebben PJ, Creo AL, Skrinar A, Mao M, et al. Rickets severity predicts clinical outcomes in children with X-linked hypophosphatemia: utility of the radiographic rickets severity score. Bone 2019;122:76-81.

22. Boyce AM, Shawker TH, Hill SC, Choyke PL, Hill MC, James R, et al. Ultrasound is superior to computed tomography for assessment of medullary nephrocalcinosis in hypoparathyroidism. J Clin Endocrinol Metab 2013;98:989-94.

23. Evan AP, Lingeman J, Coe F, Shao Y, Miller N, Matlaga B, et al. Renal histopathology of stone-forming patients with distal renal tubular acidosis. Kidney Int 2007;71:795-801.

24. Ichihara K, Yomamoto Y, Hotta T, Hosogaya S, Miyachi H, Itoh Y, et al. Collaborative derivation of reference intervals for major clinical laboratory tests in Japan. Ann Clin Biochem 2016;53:347-56.

25. Committee on Enzyme and Reagent \& Japan Society of Clinical Chemistry. About modified methods of measuring ALP and LD: for medical staff (ver.1.0) [in Japanese]. Available from: http://jsccjp.gr.jp/file/2019/alpld2.pdf [Accessed 08 Oct 2019].

26. Haffner D, Emma F, Eastwood DM, Duplan MB, Bacchetta J, Schnabel $D$, et al. Clinical practice recommendations for the diagnosis and management of X-linked hypophosphataemia. Nat Rev Nephrol 2019;15:435-55.

27. Miyamoto J, Koto S, Hasegawa Y. Final height of Japanese patients with X-linked hypophosphatemic rickets: effect of vitamin D and phosphate therapy. Endocr J 2000;7:163-7.

28. Marwaha RK, Garg MK, Dang N, Mithal A, Narang A, Chadha A, et al. Reference range of random urinary calcium creatinine ratio in North Indian children and adolescents. Ann Pediatr Endocrinol Metab 2019;24:34-40.

29. Quiñones-Vázquez S, Liriano-Ricabal MDR, Santana-Porbén S, Salabarría-González JR. Calcium-creatinine ratio in a morning urine sample for the estimation of hypercalciuria associated with non-glomerular hematuria observed in children and adolescents. Bol Med Hosp Infant Mex 2018;75:41-8.
30. Coe FL, Evan AP, Worcester EM, Lingeman JE. Three pathways for human kidney stone formation. Urol Res 2010;38:147-60.

31. Shavit L, Jaeger P, Unwin RJ. What is nephrocalcinosis? Kidney Int 2015;88:35-43.

32. Taylor A, Sherman NH, Norman ME. Nephrocalcinosis in X-linked hypophosphatemia: effect of treatment versus disease. Pediatr Nephrol 1995;9:173-5.

33. Hu H, Zhang J, Lu Y, Zhang Z, Qin B, Gao H, et al. Association between circulating vitamin $D$ level and urolithiasis: a systematic review and meta-analysis. Nutrients 2017;9:301.

34. Curhan GC, Willett WC, Speizer FE, Spiegelman D, Stampfer MJ. Comparison of dietary calcium with supplemental calcium and other nutrients as factors affecting the risk for kidney stones in women. Ann Intern Med 1997;126:497-504.

35. Wiener SV, Ho SP, Stoller ML. Beginnings of nephrolithiasis: insights into the past, present and future of Randall's plaque formation research. Curr Opin Nephrol Hypertens 2018;27: 236-42.

36. Insogna KL, Briot K, Imel EA, Kamenický P, Ruppe MD, Portale AA, et al. A randomized, double-blind, placebo-controlled, phase 3 trial evaluating the efficacy of burosumab, an anti-FGF23 antibody, in adults with X-linked hypophosphatemia: week 24 primary analysis. J Bone Miner Res 2018;33:1383-93.

37. Portale AA, Carpenter TO, Brandi ML, Briot K, Cheong HI, CohenSolal $M$, et al. Continued beneficial effects of burosumab in adults with X-linked hypophosphatemia: results from a 24-week treatment continuation period after a 24-week double-blind placebo-controlled period. Calcif Tissue Int 2019;105:271-84.

38. Martín Ramos S, Gil-Calvo M, Roldán V, Castellano Martínez A, Santos F. Positive response to one-year treatment with burosumab in pediatric patients with X-linked hypophosphatemia. Front Pediatr 2020;8:48.

39. Amir E, Simmons CE, Freedman OC, Dranitsaris G, Cole DEC, Vieth $R$, et al. A phase 2 trial exploring the effects of high-dose $(10,000 \mathrm{lU} /$ day) vitamin $\mathrm{D}(3)$ in breast cancer patients with bone metastases. Cancer 2010;116:284-91.

Supplementary Material: The online version of this article offers supplementary material (https://doi.org/10.1515/jpem-2020-0734).

Serum and urine biochemical outcomes before and after switching treatments. Serum P (a, b), ALP (c, d), and 1,25-(OH)2D (e, f) concentration were not changed $3.2 \pm 0.7$ vs. $3.2 \pm 0.4 \mathrm{mg} / \mathrm{dL}$, $1,229 \pm 371$ vs. $1,191 \pm 327 \mathrm{IU} / \mathrm{L}$, and $70.3 \pm 24.1$ vs. $65.0 \pm 16.3 \mathrm{pg} / \mathrm{mL}$ in both the conventional therapy and burosumab, respectively, but improved comparing to baseline (BL). Renal $P$ reabsorption were analyzed by TmP/GFR ( $\mathrm{g}, \mathrm{h}$ ) and \%TRP (i, j), and improved with burosumab from $2.5 \pm 0.6$ to $3.0 \pm 0.5 \mathrm{mg} / \mathrm{dL}$, and from $77.9 \pm 9.3$ to $90.6 \pm 5.3 \%$, respectively. 